\title{
Evolution of multipartite mitochondrial genomes in the booklice of the genus Liposcelis (Psocoptera)
}

\author{
Shi-Chun Chen ${ }^{1+}$, Dan-Dan Wei $^{1+}$, Renfu Shao ${ }^{2}$, Jun-Xia Shi ${ }^{1}$, Wei Dou ${ }^{1}$ and Jin-Jun Wang ${ }^{1 *}$
}

\begin{abstract}
Background: The genus Liposcelis (Psocoptera: Troctomorpha) has more than 120 species with a worldwide distribution and they pose a risk for global food security. The organization of mitochondrial (mt) genomes varies between the two species of booklice investigated in the genus Liposcelis. Liposcelis decolor has its $\mathrm{mt}$ genes on a single chromosome, like most other insects; L. bostrychophila, however, has a multipartite mt genome with genes on two chromosomes.

Results: To understand how multipartite mt genome organization evolved in the genus Liposcelis, we sequenced the mt genomes of L. entomophila and L. paeta in this study. We found that these two species of booklice also have multipartite $\mathrm{mt}$ genomes, like L. bostrychophila, with the $\mathrm{mt}$ genes we identified on two chromosomes. Numerous pseudo mt genes and non-coding regions were found in the $\mathrm{mt}$ genomes of these two booklice, and account for 30\% and 10\% respectively of the entire length we sequenced. In L. bostrychophila, the mt genes are distributed approximately equally between the two chromosomes. In L. entomophila and L. paeta, however, one mt chromosome has most of the genes we identified whereas the other chromosome has largely pseudogenes and non-coding regions. L. entomophila and L. paeta differ substantially from each other and from L. bostrychophila in gene content and gene arrangement in their mt chromosomes.
\end{abstract}

Conclusions: Our results indicate unusually fast evolution in $\mathrm{mt}$ genome organization in the booklice of the genus Liposcelis, and reveal different patterns of $\mathrm{mt}$ genome fragmentation among L. bostrychophila, L. entomophila and L. paeta.

Keywords: Mitochondrial genome, Liposcelis entomophila, Liposcelis paeta, Pseudogene, Evolution

\section{Background}

Animal mitochondrial $(\mathrm{mt})$ genomes are typically a circular DNA molecule, $13-20 \mathrm{~kb}$ in size, consisting of a control region $(\mathrm{CR})$ and 37 genes: 13 protein-coding genes (PCG), 2 ribosomal RNA genes (rRNA), and 22 transfer RNA genes (tRNA) [1-5]. The organization, gene content and gene arrangement of animal $\mathrm{mt}$ genomes are usually very conserved [4]. For insects, the ancestral $\mathrm{mt}$ genome organization is retained in most species known, although minor changes in gene arrangement were observed in several groups of insects [1,6-9].

\footnotetext{
* Correspondence: jjwang7008@yahoo.com

'Equal contributors

'Key Laboratory of Entomology and Pest Control Engineering, College of

Plant Protection, Southwest University, Chongqing, P. R. China

Full list of author information is available at the end of the article
}

The order Psocoptera (booklice and barklice) contains more than 4,400 described species in three suborders: Troctomorpha, Trogiomorpha, and Psocomorpha $[10,11]$. Complete or near complete $\mathrm{mt}$ genomes have been reported for three barklice (suborders Trogiomorpha and Psocomorpha) and two booklice (suborder Troctomorpha) [12-15]. The mt genomes of the three barklice, Lepidopsocidae sp. RS-2001 (suborder Trogiomorpha), Psococerastis albimaculata and Longivalvus hyalospilus (suborder Psocomorpha), retained largely the ancestral mt genome organization of insects with rearrangement of several genes in each species [12,14]. The mt genomes of the two booklice, Liposcelis decolor and L. bostrychophila (suborder Troctomorpha), however, are highly rearranged; only one ancestral gene arrangement, atp8-atp6, is retained. These two booklice differ even from each other in the 
organization of their mt genomes. $L$. decolor, like most other insects, has the typical single-chromosome $\mathrm{mt}$ genome of animals [15]. L. bostrychophila, however, has a multipartite mt genome with two chromosomes [13].

The genus Liposcelis has more than 120 species with a worldwide distribution [16-19]; many of them are important pests to stored grain products [20]. Liposcelis species are divided into four groups phylogenetically: A, B, C and D $[18,19,21]$. L. decolor is in the group B whereas $L$. bostrychophila is in the group D [18]. Substantial variation in morphology and physiology among Liposcelis groups has been reported previously $[17,21,22]$. To understand how multipartite $\mathrm{mt}$ genomes evolved in the genus Liposcelis, we further sequenced the mt genomes of $L$. entomophila (from group A) and L. paeta (from group D). We found that these two booklice also have multipartite $\mathrm{mt}$ genomes, like L. bostrychophila. Further, L. entomophila and L. paeta differ substantially from each other and from L. bostrychophila in gene content and gene arrangement in their mt genomes. Our results indicate an unusually fast evolution in $\mathrm{mt}$ genome organization in the booklice of the genus Liposcelis.

\section{Methods}

\section{Ethics statement}

No specific permits were required for the insects collected in this study. The sampling locations were not privately owned or protected in any way and the collection did not involve endangered or protected species.

\section{Sample collection, DNA extraction and $\mathrm{mt}$ genome amplification}

The booklice were collected at grain storage facilities. L. entomophila were collected in Beibei, Chongqing and L. paeta in Wuzhou, Guangxi, China. They were identified to species by morphology [17,23], and partial sequences of rrnL and cox1 genes [24]. Total genomic DNA was extracted from $\sim 300$ booklice specimens (20 mg) using a Tissue/Cell gDNA Mini Kit (Watson Biotechnologies, Shanghai, China) and stored at $-20^{\circ} \mathrm{C}$.

Partial sequences of cox $1, c o b, r r n S$, and $r r n L$ genes of L. entomophila were amplified initially by PCR with conserved insect primers [25]. Two pairs of primers, E1-E2 and E3-E4, were designed from cox1 and cob genes (Additional file 1). Two overlapping fragments were amplified by long PCR with E1 - E2 and E3-E4, sequenced and assembled into a contig (L. entomophila chromosome I) with SeqMan (DNAStar). The non-coding sequence, which contains the sites for genome replication and the initiation of gene transcription, is always shared by all of mini-chromosomes of a fragment $\mathrm{mt}$ genome $[13,26,27]$. Thus, a primer (E6) has been designed from a non-coding region (NCRI-1) in L. entomophila chromosome I. Another primer (E5) was designed from $r r n L$ gene.
With E5 - E6, a 10,231 bp long fragment was amplified and sequenced. A pair of outbound primers (E7 and E8) was designed from this fragment, and a complementary sequence of E5 - E6 was amplified. These two fragments were assembled into a contig. For L. paeta, fragments of nad5, rrnS and $r r n L$ genes were amplified initially; four pairs of primers (P1-P2, P3-P4, P5-P6 and P7-P8) were designed from these three gene fragments. Then, four fragments were amplified with these four pairs of primers, and were assembled into two contigs (L. paeta chromosome I and II). To verify L. paeta chromosome II and avoid the mistake might be caused by primers (P6 and P8) at pseudogene PrrnL-2, a 3,412 bp fragment was amplified additionally with primers P9-P10 (Additional file 2).

Each long PCR reaction is $25 \mu \mathrm{L}$ in volume, containing $1.0 \mu \mathrm{L}$ each of forward primer $(10 \mu \mathrm{M})$ and reverse primer $(10 \mu \mathrm{M}), 4.0 \mu \mathrm{L}$ of dNTPs mix (each $2.5 \mathrm{mM}$ ), $1.0 \mu \mathrm{L}$ of template DNA, $2.5 \mu \mathrm{L} \mathrm{MgCl}_{2}(25 \mathrm{mM}), 2.5 \mu \mathrm{L}$ of $10 \times \mathrm{LA}$ PCR reaction buffer II, $12.75 \mu \mathrm{L} \mathrm{ddH}_{2} \mathrm{O}$ and $0.25 \mu \mathrm{L}$ LA Taq DNA polymerase (5 U/ $\mu \mathrm{L}$, Takara). All reactions were carried out using $\mathrm{C} 1000^{\mathrm{TM}}$ thermal cyclers (Bio-RAD, Hercules, CA, USA) with the follow conditions: 2 min denaturation at $94^{\circ} \mathrm{C}, 37$ cycles of $94^{\circ} \mathrm{C}$ for $20 \mathrm{~s}, 58^{\circ} \mathrm{C}$ for $50 \mathrm{~s}, 68^{\circ} \mathrm{C}$ for $5-10 \mathrm{~min}$ (depending on target size, $1 \mathrm{~min} / \mathrm{kb}$ ), followed by a final extension at $68^{\circ} \mathrm{C}$ for $15 \mathrm{~min}$. Gel-purified amplification products $<5 \mathrm{~kb}$ in size were ligated into pGEM-T Easy vectors (Promega, Madison, WI, USA), and introduced into Escherichia coli (Trans5 $\alpha$, Beijing TransGen Biotech, Beijing, China). Followed by ampicillin selection, plasmid DNAs from positive clones were sequenced with M13 primers. Longer PCR products $(>5 \mathrm{~kb})$ were directly sequenced with both forward and reverse PCR primers and internal primers by primer walking. All products were sequenced by Life Technologies in Guangzhou, China.

\section{Sequence annotation and analysis}

The protein-coding genes (PCGs) were identified by the ORF Finder (http://www.ncbi.nlm.nih.gov/gorf/gorf.html) and rRNA genes by BLAST searches, then confirmed by alignment with homologous genes from those of other booklouse and louse species (Additional file 3). The transfer RNA genes were identified by cloverleaf secondary structure using ARWEN [28] with default parameters and tRNAscan-SE 1.21 [29] with the parameters: Search Mode $=$ "EufindtRNA-Cove", Genetic Code = "Invertebrate Mito" and Cove score cutoff $=0.1$. We used Mfold Server [30] in RNA folding form with default parameters to construct the typical stem-loop secondary structure of putative control region. The base composition was analyzed with BioEdit (http://bioedit.software.informer.com/). Sequences of $\mathrm{mt}$ genomes of other lice and booklice were retrieved from GenBank and MitoZoa [31] (Additional file 3). 


\section{Phylogenetic analyses}

We conducted phylogenetic analyses of the mt genome sequences of seven species of Psocoptera and thirteen species of Phthiraptera. The mt genome sequence of Drosophila melanogaster was used as an outgroup. Sequences of all protein-coding genes and rRNA genes except atp 8 and nad4L were used in phylogenetic analyses. atp8, nad4L and tRNA genes were excluded because they are too short to align among the psocodean species. Two alignments were used for phylogenetic analyses: 1) a concatenated nucleotide sequence alignment of protein-coding genes and two rRNA genes (Additional file 4); 2) a concatenated amino acid sequence alignment of eleven protein-coding genes (Additional file 5). Nucleotide sequences of all protein-coding genes were aligned at the amino acid level using the default settings in ClustalW as implemented in MEGA 5 [32]; the alignments were then back-translated into the corresponding nucleotide sequences. Amino acid sequences of PCGs were aligned in ClustalW; All of the alignments were then imported into the Gblocks server (http://molevol.cmima. csic.es/castresana/Gblocks_server.html) to remove poorly aligned sites [33]. Gblocks server was applied with the 'codons', 'DNA' and 'protein' mode respectively for PCG nucleotide sequences, rRNA sequences and PCG amino acid sequences, and with all options for a stringent selection were chosen. Substitution saturations of the nucleotide sequences were examined using DAMBE 5.3.9 [34]. Whole PCG nucleotide sequences were selected to enter the next step if Iss (index of substitution saturation) was significantly lower than Iss.c (critical value for symmetrical tree topology $(P<0.05)$. All of the protein-coding genes, except nad2 and nad3, passed this test; the third codon positions of nad2 and nad3 were thus excluded from our phylogenetic analyses. The best fit models for the alignment of nucleotide sequence and amino acid sequence were determined using the Akaike Information Criterion in jModelTest 2.1.4 [35,36] and ProtTest 3.2 [37], then the $\mathrm{GTR}+\mathrm{I}+\mathrm{G}$ model and MtArt $+\mathrm{I}+\mathrm{G}+\mathrm{F}$ model were chosen. Phylogenetic trees were constructed from the dataset using maximum likelihood (ML) method. ML analyses were performed using PhyML3.0 (http://www.atgcmontpellier.fr/phyml/) [38] with substitution model 'GTR' or 'MtArt', type of tree improvement "SPR \& NNI", and the shape parameter and the propotion of invariable sites was estimated by jModelTest 2.1.4 and ProtTest 3.2.

\section{Results}

Mitochondrial genomes of $L$. entomophila and $L$. paeta

The mt genome of L. entomophila consists of two circular chromosomes, I (GenBank Accession No. KF649223) and II (GenBank Accession No. KF649224). Chromosome I, 11,599 bp long, was assembled from two overlapping PCR amplicons, 5,634 bp (E1 - E2) and 6,413 bp (E3 - E4), respectively (Figures $1 \mathrm{~A}$ and $2 \mathrm{~A}$ ). These two amplicons overlap by $64 \mathrm{bp}$ in $\operatorname{cox} 1$ and $284 \mathrm{bp}$ in $c o b$. The other two amplicons, E5 - E6 (10,231 bp) and E7 - E8 (3,353 bp), were assembled to form chromosome II, 12,675 bp long; these two amplicons overlap by $347 \mathrm{bp}$ in $r r n L$ and $470 \mathrm{bp}$ in NCRII-3 (Figures 1A and 2A). Totally, 28 of the $37 \mathrm{mt}$ genes typical of bilateral animals and 15 pseudogenes were found in the two $\mathrm{mt}$ chromosomes of L. entomophila. Chromosome I contains 11 protein-coding genes (atp6, cob, cox1-cox3, and nad1-nad6) and three pseudogenes. Chromosome II contains two rRNA genes ( $r r n L$ and $r r n S$ ), 14 tRNA genes (trnD, trnF, trnI, trnK, trnL1, trnL2, trnM, trnP, trnQ, trnR, trnS1, trnS2, trnT and trnY) and a PCG
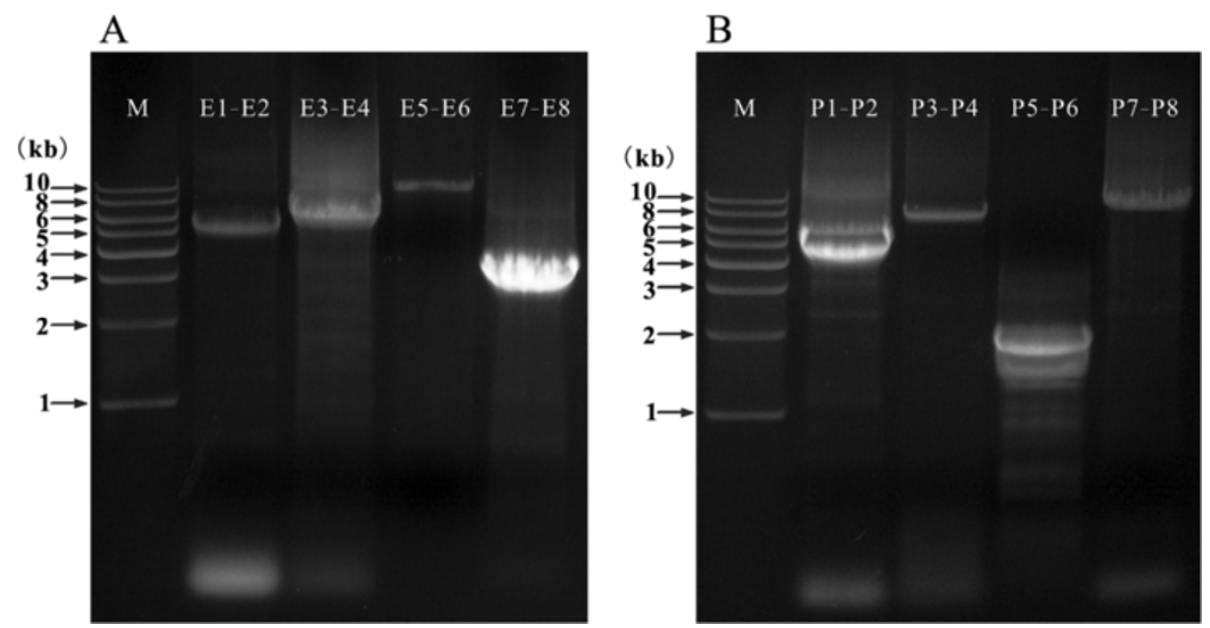

Figure 1 PCR amplicons from mitochondrial DNA of Liposcelis entomophila (A) and L. paeta (B). Lane M: 1 kb marker (Biomed). "E1-E2", the product of PCR with primers E1 and E2, etc. Details of primers are in Additional files 1 and 2. 

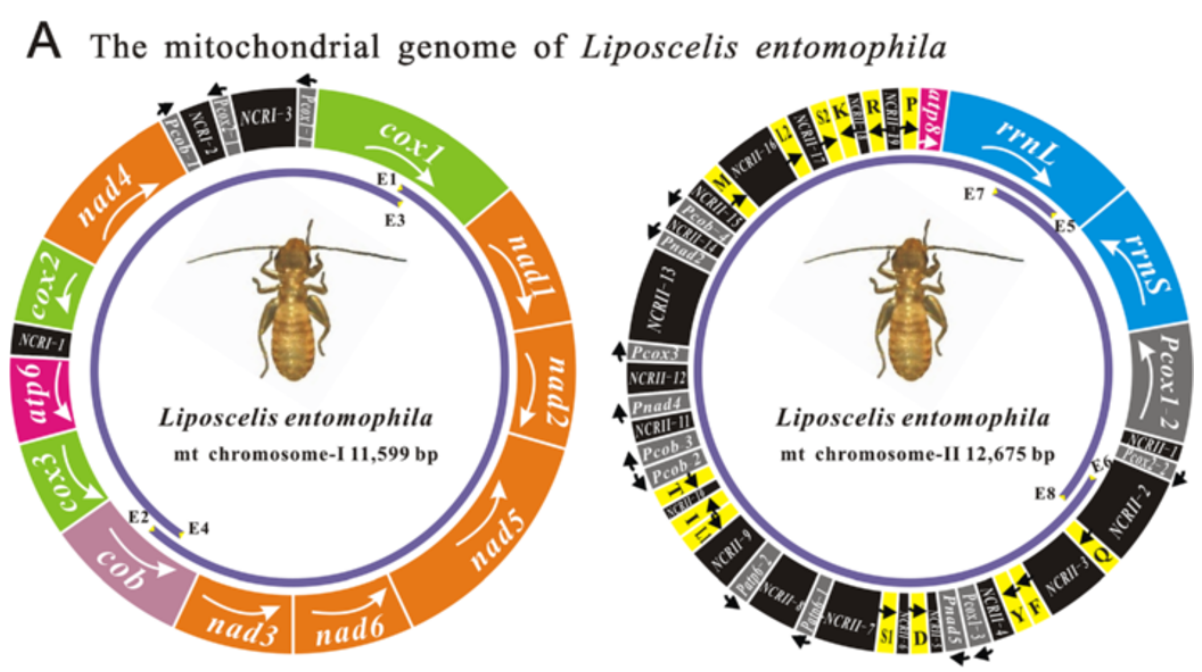

B The mitochondrial genome of Liposcelis paeta
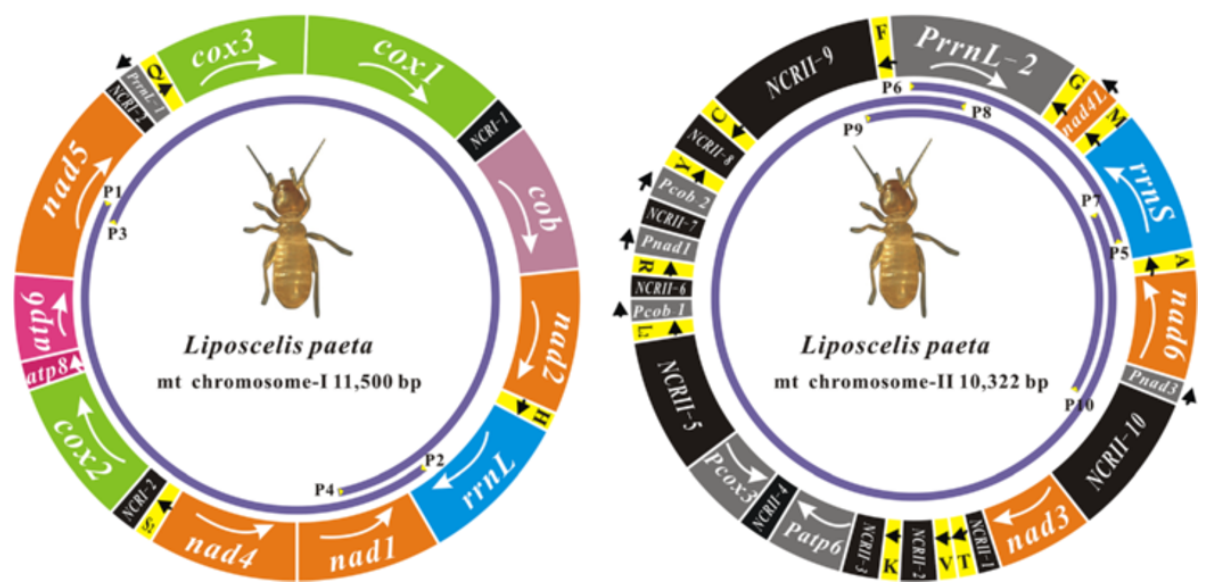

Figure 2 The mitochondrial genomes of Liposcelis entomophila (A) and L. paeta (B). The transcriptional orientation is indicated with arrows. Protein-coding genes, ribosomal RNA genes and transfer RNA genes are shown in bright colors. All of them in the map follow standard abbreviations. tRNA genes for the two serine and two leucine tRNAs: $S_{1}=A G N, S_{2}=U C N, L_{1}=C U N$ and $L_{2}=U U R$. Pseudogenes are shown in gray. The non-coding sequences $>100 \mathrm{bp}$ are indicated in black. Arrows and purple curves indicate primers and PCR fragments, respectively. See Additional files 1 and 2 for PCR primers.

(atp8) (Figure 2A and Additional file 6). Additionally, 12 pseudogenes were also found on this chromosome (Figure 2A and Additional file 7).

The mt genome of $L$. paeta also had two chromosomes: I (GenBank Accession No. KF649226) and II (GenBank Accession No. KF649225). These two chromosomes were $11,500 \mathrm{bp}$ and 10,322 bp long. Chromosome I was assembled from two overlapping fragments, P1 - P2 (4,885 bp) and P3 - P4 (7,659 bp). Chromosome II was assembled from P5 - P6 (1,860 bp) and P7 - P8 (8,908 bp). P1 - P2 and P3 - P4 overlap by 218 bp in nad5 and 731 bp in rrnL, and the other two fragments overlap by $117 \mathrm{bp}$ in $r r n S$ and 233 bp in PrrnL-2 (Figures $1 \mathrm{~B}$ and 2B). To verify these contigs, a 3,412 bp fragment (P9-P10) was amplified additionally with primers P9-P10 (Additional file 2). We found 29 of the $37 \mathrm{mt}$ genes typical of bilateral animals and 8 pseudogenes in L. paeta. Chromosome I contains 10 protein-coding genes (atp6, atp8, cob, cox1-cox3, nad1, nad2, nad4, and nad5), an rRNA gene ( $r r n L)$, three tRNA genes (trnS2, trnQ, and trnH) and a pseudogene. Chromosome II contains three protein-coding genes (nad3, nad4L, and nad6), rrnS, 11 tRNA genes (trnA, trnC, trnF, trnG, trnK, trnL2, trnM, trnR, trnT, trn $V$ and trnY) and seven pseudogenes (Figures 2B, Additional files 6 and 8).

The mt gene arrangements of $L$. entomophila and $L$. paeta differ from that of the hypothetical ancestor of insects, from that of the other booklice and from each other. L. entomophila shares no mt gene boundary with the hypothetical ancestor of insects, L. paeta, L. bostrychophila, and L. decolor. For L. paeta, only atp8-atp6 is 
shared with the hypothetical ancestor of insects, L. bostrychophila and L. decolor, and cox3-cox1 and nad4nad1 are shared with L. bostrychophila, which is also from the group D of Liposcelis species (Figure 3).

\section{Pseudogenes and non-coding sequences}

We identified 15 and 8 pseudo mt genes in L. entomophila and $L$. paeta, respectively (Table 1 ). The total length of all of the 15 pseudogenes in L. entomophila is 2,555 bp, which accounts for $10.53 \%$ of the total length of the two chromosomes. For L. paeta, the total length of all of the 8 pseudogenes is $2,466 \mathrm{bp}$, which accounts for $11.30 \%$ of the two mt chromosomes we sequenced. Each of the mt pseudogenes is a partial sequence of a protein-coding gene or an rRNA gene with several nucleotides changed, and has a high similarity $(>85 \%)$ to the homologous sequence in functional gene (Table 1). For instance, Pcox1-2 of L. entomophila, located on the chromosome II, is 847 bp long and is identical to the part of cox 1 from 163 to $1,009 \mathrm{bp}$ except for a single nucleotide change (Additional file 9).

Non-coding sequences also account for large proportions of the mt chromosomes of L. entomophila and L. paeta.
The non-coding sequences are 8,912 bp and 6,391 bp long, in total, for L. entomophila and L. paeta, and account for $36.72 \%$ and $29.29 \%$ of the entire length of their $\mathrm{mt}$ chromosomes. There are 22 and 13 non-coding sequences that are longer than $100 \mathrm{bp}$ in the $\mathrm{mt}$ chromosomes of L. entomophila and L. paeta, respectively. For both L. entomophila and L. paeta, pseudogenes and non-coding sequences are largely on one of the mt chromosomes (chromosome II), whereas coding sequences are on the other chromosome (chromosome I) (Figures 2 and 4). Intriguingly, partial sequences are shared by three or two non-coding regions in L. entomophila and L. paeta. Three non-coding regions (NCRI-1, NCRI-3 and NCRII-2) of L. entomophila, each two of the three share a consistent sequence, and a partial sequence is common in all of the three. In $L$. paeta, two non-coding regions from $\mathrm{mt}$ chromosome II (NCRII-5 and NCRII-10) contain the same 286 bp sequence with two nucleotides change (Figure 5).

\section{Phylogenetic relationships among species of Psocodea}

We analyzed the mt genome sequences with maximum likelihood (ML) method to infer the phylogenetic relationship

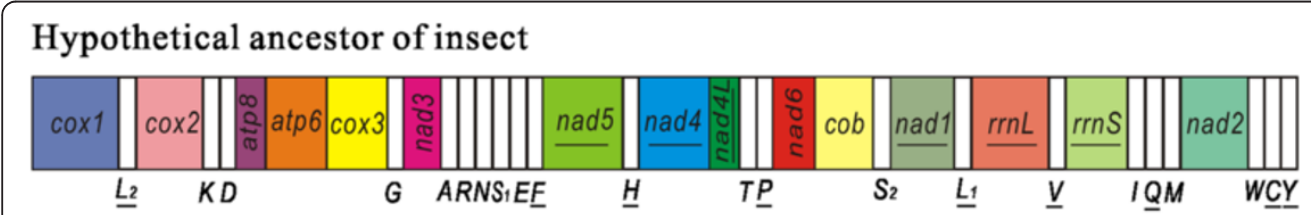

\section{Liposcelis decolor (Psocoptera, Troctomorpha)}

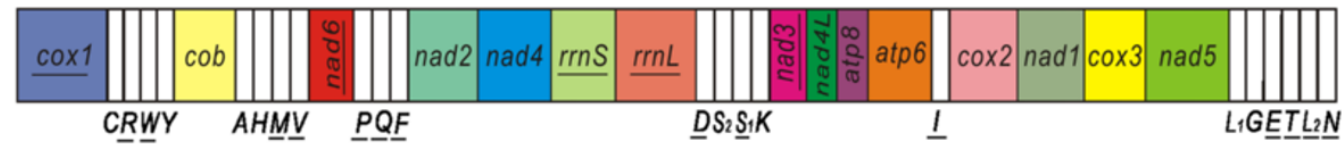

\section{Liposcelis entomophila (Psocoptera, Troctomorpha)}

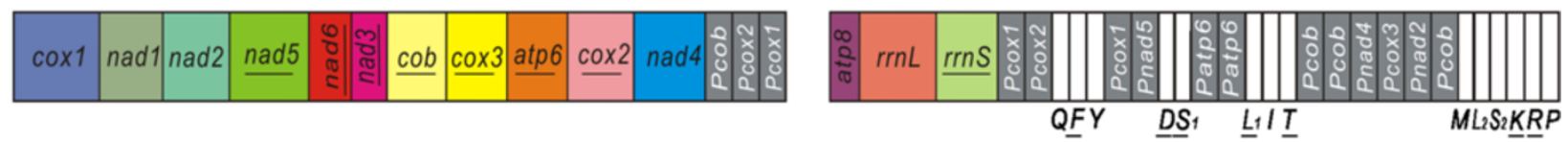

\section{Liposcelis paeta (Psocoptera, Troctomorpha)}
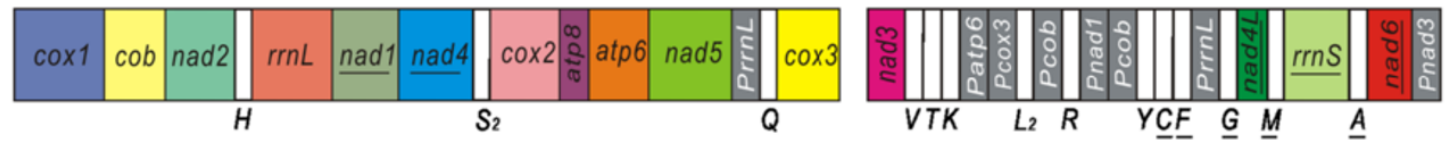

Liposcelis bostrychophila (Psocoptera, Troctomorpha)
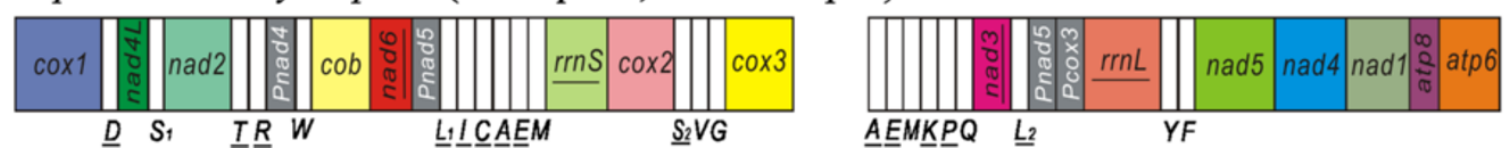

Figure 3 Arrangement of mitochondrial genes in Liposcelis and the hypothetical ancestor of the insect. Circular genomes have been arbitrarily linearized for ease of comparison. Gene names are the standard abbreviations used in the present study. tRNA genes are designated by the single letter according to the IPUC-IUB one-letter amino acid codes. Genes which are underlined are encoded on the opposite strand to the majority of genes in that particular genome. Gray and white boxes represent pseudogenes and transfer RNA genes, respectively. The boxes in bright colors represent 13 protein-coding genes and 2 ribosomal RNA genes. 
Table 1 Pseudogenes in the mitochondrial genomes of Liposcelis entomophila and L. paeta

\begin{tabular}{|c|c|c|c|c|}
\hline Species & Pseudogene & Size & $\begin{array}{l}\text { Counterpart in } \\
\text { full-length gene }\end{array}$ & Identity (\%) \\
\hline L. entomophila & Patp6-1 & 49 & $454-502$ & 100.00 \\
\hline L. entomophila & Patp6-2 & 98 & $543-642$ & 98.00 \\
\hline L. entomophila & Pcob-1 & 44 & $1025-1068$ & 90.91 \\
\hline L. entomophila & Pcob-2 & 186 & $212-399$ & 97.87 \\
\hline L. entomophila & Pcob-3 & 207 & 834-1048 & 86.76 \\
\hline L. entomophila & Pcob-4 & 119 & $366-484$ & 99.16 \\
\hline L. entomophila & Pcox1-1 & 122 & $1005-1130$ & 95.24 \\
\hline L. entomophila & Pcoxi-2 & 847 & 163-1009 & 99.88 \\
\hline L. entomophila & PCOX1-3 & 191 & $270-460$ & 99.48 \\
\hline L. entomophila & Pcox2-1 & 124 & $290-413$ & 100.00 \\
\hline L. entomophila & Pcox $2-2$ & 129 & $530-660$ & 97.71 \\
\hline L. entomophila & Pcox3 & 74 & $18-91$ & 98.65 \\
\hline L. entomophila & Pnad2 & 108 & $650-757$ & 90.74 \\
\hline L. entomophila & Pnad4 & 125 & $689-810$ & 89.60 \\
\hline L. entomophila & Pnad5 & 132 & $297-429$ & 99.25 \\
\hline L. paeta & Patp6 & 562 & $96-657$ & 99.82 \\
\hline L. paeta & Pcob-1 & 62 & $772-833$ & 100.00 \\
\hline L. paeta & Pcob-2 & 92 & $870-961$ & 98.91 \\
\hline L. paeta & Pcox3 & 422 & $237-660$ & 98.82 \\
\hline L. paeta & Pnad1 & 62 & $680-741$ & 98.39 \\
\hline L. paeta & Pnad3 & 164 & $144-315$ & 95.35 \\
\hline L. paeta & PrrnL-1 & 188 & 836-1025 & 94.24 \\
\hline L. paeta & Prrnl-2 & 914 & $111-1025$ & 99.02 \\
\hline
\end{tabular}

of L. entomophila, L. paeta, L. bostrychophila, L. decolor and with other species of Psocodea (Figure 6). In the phylogenetic tree, the four Liposcelis species were clustered together with strong support (100\% bootstrap values). Within the genus Liposcelis, L. paeta formed a clade with $L$. bostrychophila; these two species, which were from group D [18], were most closely related to L. entomophila (group A).

\section{Discussion}

Variation in the pattern of multipartite mt genome evolution among the three Liposcelis species

While $L$. decolor has the typical one-chromosome $\mathrm{mt}$ genome, like most other insects and animals. $L$. entomophila, L. paeta and L. bostrychophila have multipartite $\mathrm{mt}$ genomes. For these three Liposcelis species, there are extensive variations in the pattern of multipartite $\mathrm{mt}$ genome evolution. Firstly, the presence of numerous pseudogenes and non-coding sequences in L. entomophila and $L$. paeta makes their $\mathrm{mt}$ genomes much larger than that of L. bostrychophila (16,463 bp) (Figure 4). Furthermore, the three Liposcelis species that have multipartite mt genomes differ from each other in the distribution of $\mathrm{mt}$ genes, pseudogenes, and non-coding sequences between the $\mathrm{mt}$ chromosomes. The two $\mathrm{mt}$ chromosomes of $L$. bostrychophila contain nearly equal amounts of genes, pseudogenes and non-coding sequences. For L. entomophila and L. paeta, however, most of the $\mathrm{mt}$ genes are on one chromosome, whereas pseudogenes and non-coding sequences are on the other chromosome (Figures 2 and 4). For numerous non-coding sequences, the two $\mathrm{mt}$ chromosomes of $L$. bostrychophila contain the same major non-coding region (NCRI-4 and NCRII-3) [13]. However, three non-coding regions from two chromosomes of L. entomophila share partial sequences and two non-coding regions from $\mathrm{mt}$ chromosome II of $L$. paeta share a 286 bp sequence (Figure 5). For fragmented $\mathrm{mt}$ genome of blood-sucking lice [26,27,39-41] and the rotifers [42,43], mini-chromosomes usually have similar major non-coding sequences. The arrangement of $\mathrm{mt}$ genes varies extensively among the three Liposcelis species; indeed, no gene boundary is shared by the three booklice. The two group-D species, L. paeta and L. bostrychophila, share three gene boundaries, atp8-atp6, cox3-cox1 and nad4-nad1 (Figure 3). Prior to this study, intra-genus variations of $\mathrm{mt}$ gene arrangement have been reported in several animal genera, such as Haematopinus [39], Polyplax [40], Brachionus [42], Ciona [44], Phallusia [45], Corallium [46], Schistosoma [47], Leptotrombidium [48,49], and Dermatophagoides [50]. However, the extent of variation in these genera is much lower than that in the genus Liposcelis.

\section{Pseudo mt genes and duplicated non-coding sequences in the Liposcelis species}

Prior to the present study, pseudo mt genes have been described in L. bostrychophila and numerous other animals. Most of the pseudo mt genes are short and derived from tRNAs [40,51-56]. Pseudo $\mathrm{mt}$ genes longer than $100 \mathrm{bp}$, derived from protein-coding genes, were also reported $[13,57-60]$. Mt gene rearrangements are usually explained by a tandem duplication-random loss (TDRL) model $[61,62]$, and pseudo $\mathrm{mt}$ genes are considered to be redundant genes in the process of being eliminated [53,54,57]. The large numbers of pseudo $\mathrm{mt}$ genes we found in $L$. entomophila and L. paeta in this study and in L. bostrychophila [13] are extraordinary for insects and animals, indicating that large-scale changes, such as tandem duplication or mt chromosome duplication, occurred relatively recently in the multipartite $\mathrm{mt}$ genomes of these booklice. Intriguingly, no pseudo mt gene has been found in $L$. decolor, although it also has numerous gene rearrangements like the other three Liposcelis species that have multipartite $\mathrm{mt}$ genomes [15]. It infers that $\mathrm{mt}$ genome fragmenting is the important inducement for pseudo $\mathrm{mt}$ gene appearance in booklice. For fragmented $\mathrm{mt}$ genomes, 


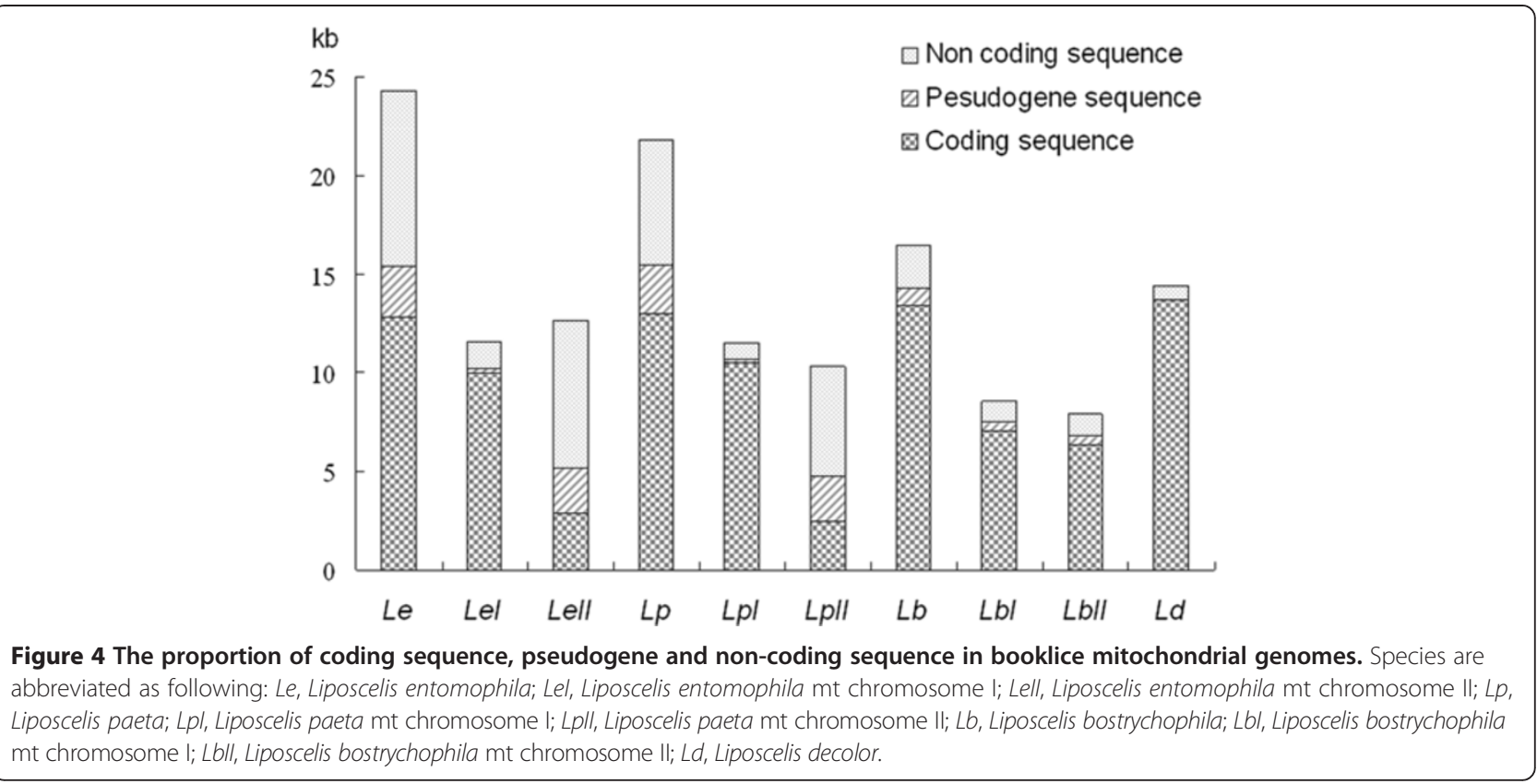

mt pseudogenes were found in the human pubic louse [26], the Polyplax rat lice [40], the Globodera nematodes $[59,60]$ and the chimeric mt minichromosomes of the human body louse [63]. The explanation for the pseudo $\mathrm{mt}$ gene present in these species is that a recombinatorial mechanism is responsible for their production. This explanation may be applicable for multipartite $\mathrm{mt}$ genome in Liposcelis, pseudo mt gene would be residues of interchromosome recombination. Duplicated non-coding sequence present coincided with pseudo $\mathrm{mt}$ gene in booklice multipartite mt genomes. The sequences, "cox $2+$ NCRI-1" from chromosome I and "Pcox2-2 + NCRII-2" from chromosome II in L. entomophila, have a $98.95 \%$ similarity and four nucleotides changed (Figure 7). This indicats that "Pcox2-2+ NCRII-2" is generated as an entire block and derived from "cox $2+N C R I-1$ ". Therefore, the causation of duplicated non-coding sequences present in booklice might be consistent with that of pseudo mt genes. The same situation has also been found in L. bostrychophila [13] and human body louse [63].

\section{Phylogenetic relationships among Liposcelis species inferred from mitochondrial genome sequences and organization}

Although $L$. decolor differ from the other three Liposcelis species in $\mathrm{mt}$ genome organization, these four booklice are more closely related to each other than to other species in the Psocodea, that also echoes previous researches $[16-18,23]$. In the phylogenetic tree, L. decolor (group B), representing the booklice with typical single chromosome mt genome, was split off from the others firstly, and the three booklice with multipartite mt genome were clustered into the same branch. This was also indicated by sequence analysis of the ribosomal internal transcribed spacers region [21]. This suggested that the multipartite $\mathrm{mt}$ genome organization observed in booklice likely evolved recently after $L$. decolor split from the most recent common ancestor. However, all of the bloodsucking lice (suborder Anoplura) in a branch have extreme fragmented $\mathrm{mt}$ genomes, that $\mathrm{mt}$ genome fragment began from the common ancestor of the suborder Anoplura. It can be inferred that the multipartite mt genome organization in Liposcelis evolved independently from fragmented $\mathrm{mt}$ genomes exist in the blood-sucking lice. For three booklice with multipartite mt genome, L. paeta (group D) and L. bostrychophila (group D) were clustered together, and formed a sister clade to L. entomophila (group A). This result is consistent with the previous studies $[17,21,23]$ and can be concluded by mt gene arrangement analyses. L. paeta share three gene boundaries with L. bostrychophila, but share none of gene boundary with L. entomophila. However, genome size, gene distribution and $\mathrm{A}+\mathrm{T}$ content show L. entomophila and L. paeta have more close relationship to each other. Mt gene rearrangement is a common phenomenon in Psocodea, and is occurred even more seriously in booklice. The gene boundaries shared by L. paeta and L. bostrychophila as powerful evidences to support the close relationship between them. Then, the disparities of genome size, gene distribution and $\mathrm{A}+\mathrm{T}$ content may indicate different evolution speeds and patterns of multipartite mt genome in Liposcelis species. 


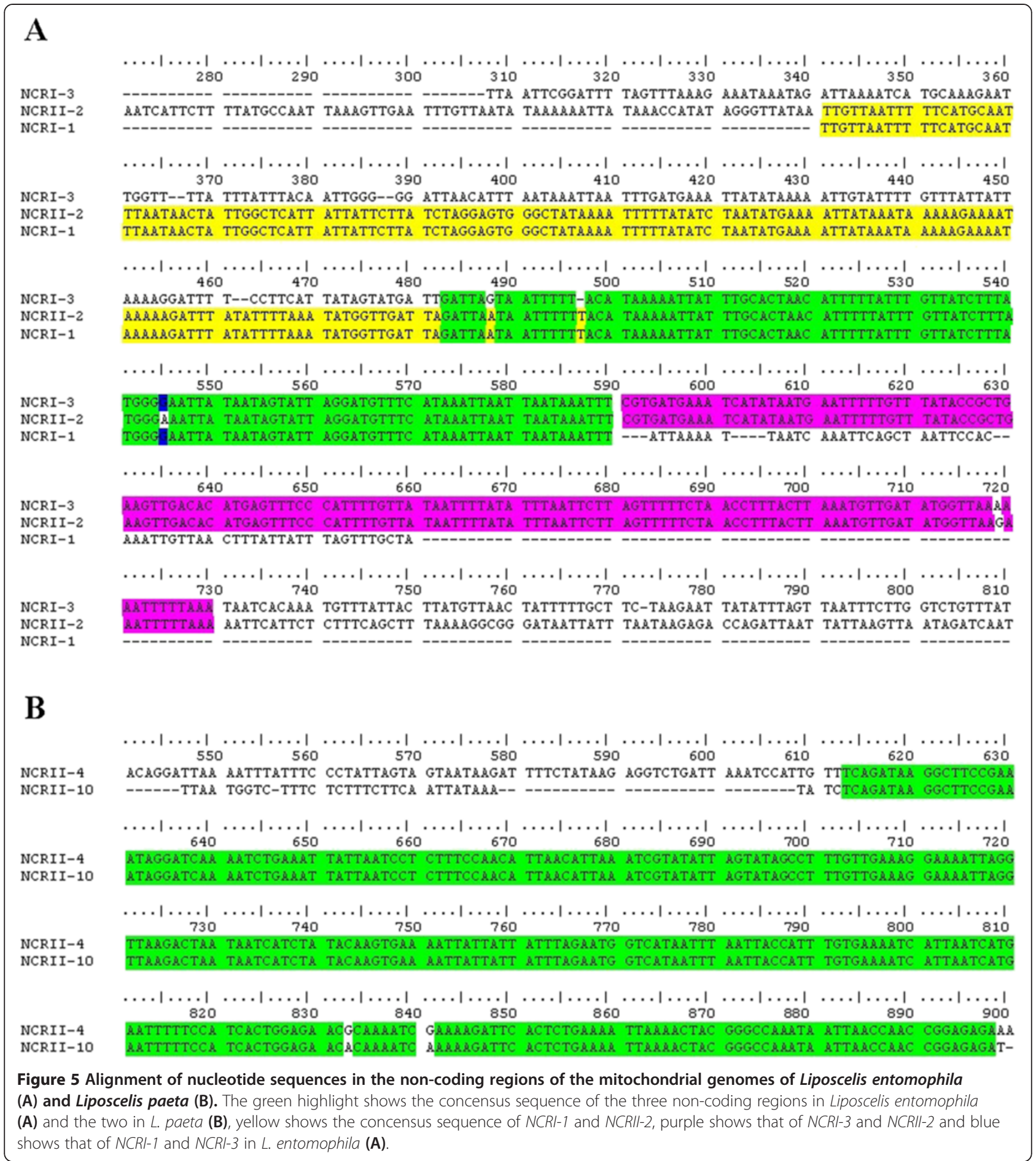

\section{Conclusions}

We sequenced the complete mitochondrial genome of the booklice, L. entomophila and L. paeta. Both of these two mitochondrial genomes are multipartite like $L$. bostrychophila. Numerous pseudogenes and non-coding regions have been found in these $\mathrm{mt}$ genomes, and one $\mathrm{mt}$ chromosome has most of protein-coding genes whereas the other chromosome has largely pseudogenes and non-coding regions. However, the $\mathrm{mt}$ genes are distributed approximately equally between the two chromosomes in L. bostrychophila. L. entomophila and L. paeta differ substantially from each other and from L. bostrychophila in gene content and gene arrangement in their $\mathrm{mt}$ chromosomes. Although the 


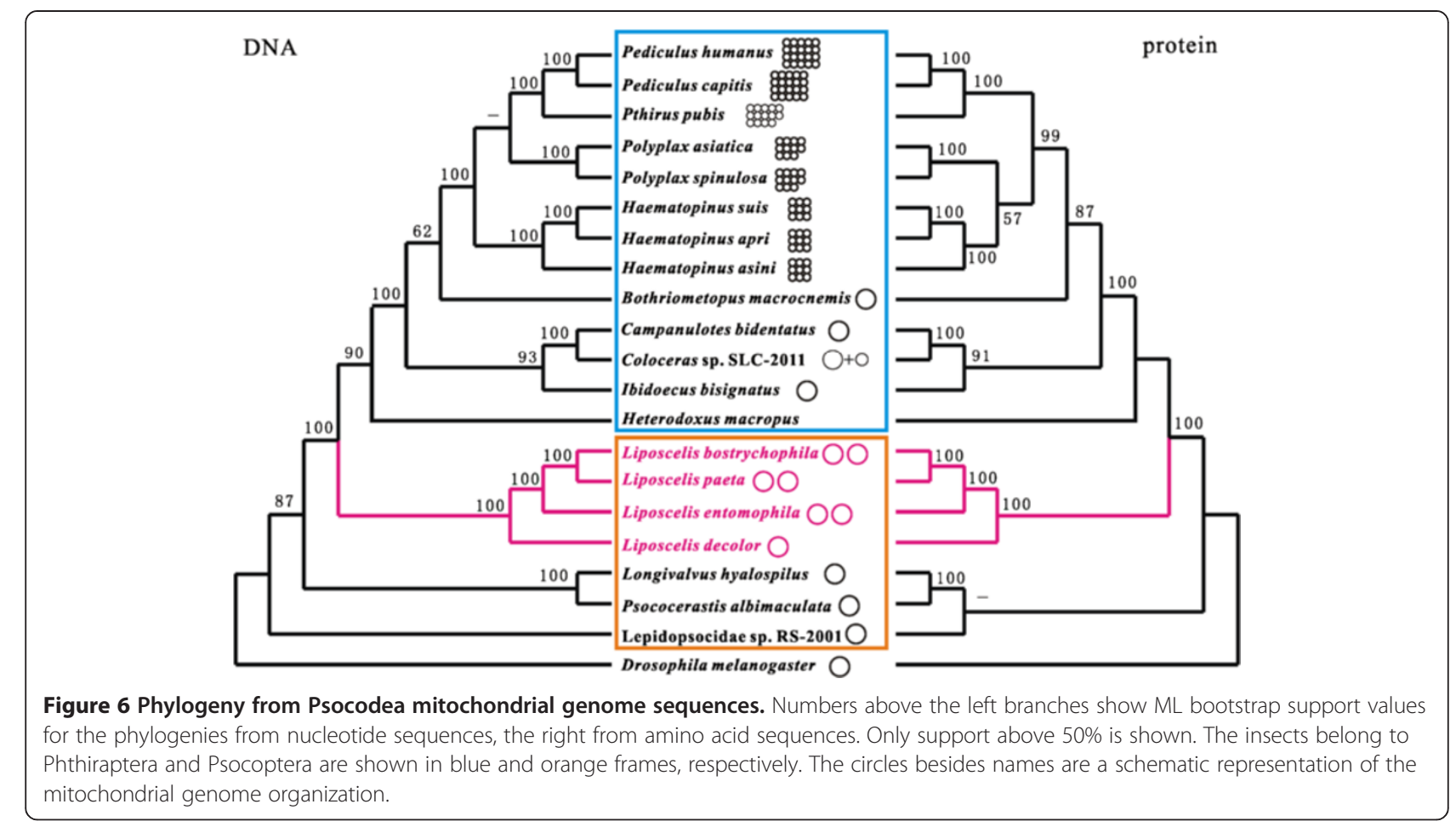

four Liposcelis species are different from each other in $\mathrm{mt}$ genome organization, they were clustered together with strong support in the phylogenetic tree. Then, these results indicate unusually fast evolution in $\mathrm{mt}$ genome organization in the booklice of the genus Liposcelis, and reveal different patterns of $\mathrm{mt}$ genome fragmentation among L. bostrychophila, L. entomophila and L. paeta.

\section{Availability of supporting data}

The data sets supporting the results of this article are included within the article and its additional files. The nucleotide sequences of the $\mathrm{mt}$ genomes of the two booklice supporting the results of this article have been deposited in GenBank (accession numbers KF649223KF649226). Phylogenetic data are available in TreeBase under study number 16391.

\section{$381 \mathrm{bp}, 98.95 \%$ similarity \\ PCOx2-2+NCRII-2 $\operatorname{cox} 2+\mathrm{NCRI}-1$ \\ Pco $2-2+$ NCRII-2 Cox $2+\mathrm{NCRI}-1$ \\ PCOX2-2+NCRII-2 $\operatorname{cox} 2+\mathrm{NCRI}-1$ \\ Pcox 2-2+NCRII-2 Cox $2+\mathrm{NCRI}-1$ \\ Pcox2-2+NCRII-2 COX2+NCRI-1 \\ ATTTGTTTAG GTTCCGGACA GGTTGATTTT ATGGTCAGTG TTCTGAAMT TGTGGAGTTA ATCATTCTTT TATGCCAATT \\ AAAGTTGART TTGTTAATAT AAAAAA--TT ATAAACCATA TAGGGTATA ATTGTTAATT TTTCATGCAA TTTAATAACT AARGTTGAT TTGTTARAT AAAAAATT ATAARCATA TAGGTTATA ATTGTTARTT TTTCATGCAA TTTARTACT \\ ATTGGCTCAT TATTATTCTT ATCTAGGAGT GGGCTATARA ATTTTTATAT CTAATATGAA AATTATARAT AARAGAARA ATTGGCTCAT TATTATTCTT ATCTAGGAGT GGGCTATAA ATTTTTATAT CTAATATGA AATTATAART AAAAGAAA \\ Figure 7 Alignment of nucleotide sequences of "cox2 + NCRI-1" from chromosome I and "Pcox2-2 + NCRII-2" in Liposcelis entomophila. Consensus sequences are shown in the green background.}




\section{Additional files}

\section{Additional file 1: PCR primers used for amplification of the mitochondrial genome of Liposcelis entomophila. \\ Additional file 2: PCR primers used for amplification of the mitochondrial genome of Liposcelis paeta.}

Additional file 3: Species of insects included in phylogenetic analysis in this study.

Additional file 4: Alignments of nucleotide sequence used for phylogenetic inference. Species are abbreviated as following: LP, Liposcelis paeta; Le, Liposcelis entomophila; Lb, Liposcelis bostrychophila; Ld, Liposcelis decolor; Lh, Longivalvus hyalospilus; Pa, Psococerastis albimaculata; Ls, Lepidopsocidae sp. RS-2001; Bm, Bothriometopus macrocnemis; Cb, Campanulotes bidentatus; Cs: Coloceras sp. SLC-2011; Hm, Heterodoxus macropus; Ib, Ibidoecus bisignatus; Pc, Pediculus capitis; Ph, Pediculus humanus; Pp, Pthirus pubis; Hs, Haematopinus suis; $\mathrm{Ha}$, Haematopinus apri; Has: Haematopinus asini; Poa, Polyplax asiatica; Pos, Polyplax spinulosa; Dm, Drosophila melanogaster

Additional file 5: Alignments of amino acid sequence used for phylogenetic inference. Species are abbreviated as following: LP, Liposcelis paeta; Le, Liposcelis entomophila; Lb, Liposcelis bostrychophila; Ld, Liposcelis decolor; Lh, Longivalvus hyalospilus; Pa, Psococerastis albimaculata; Ls, Lepidopsocidae sp. RS-2001; Bm, Bothriometopus macrocnemis; Cb, Campanulotes bidentatus; Cs: Coloceras sp. SLC-2011; $\mathrm{Hm}$, Heterodoxus macropus; Ib, Ibidoecus bisignatus; Pc, Pediculus capitis; Ph, Pediculus humanus; Pp, Pthirus pubis; Hs, Haematopinus suis; $\mathrm{Ha}$, Haematopinus apri; Has: Haematopinus asini; Poa, Polyplax asiatica; Pos, Polyplax spinulosa; Dm, Drosophila melanogaster

Additional file 6: Putative secondary structures of the tRNA genes identified in the mitochondrial genome of Liposcelis entomophila $(L e)$ and $L$. paeta $(L p)$. Bars indicate Watson-Crick base pairings, and dots between $G$ and $U$ pairs mark canonical base pairings appearing in RNA.

Additional file 7: Summary of the mitochondrial genome of Liposcelis entomophila. ${ }^{a}$ genes and pseudogenes located in the different strand from that of $\operatorname{cox} 1$ are underlined. ${ }^{\text {binc }}=$ intergenic nucleotides, indicates gap nucleotides (positive value) or overlapped nucleotides (negative value) between two adjacent genes. ${ }^{\mathrm{C}} \mathrm{AT}$-skew $=$ $(A-T) /(A+T), G C$-skew $=(G-C) /(G+C) .{ }^{d}$ genes and pseudogenes located in the different strand from that of atp8 are underlined.

Additional file 8: Summary of the mitochondrial genome of Liposcelis paeta. ${ }^{\text {agenes }}$ and pseudogenes located in the different strand from that of cox 1 are underlined. ${ }^{b}$ inc $=$ intergenic nucleotides, indicates gap nucleotides (positive value) or overlapped nucleotides (negative value) between two adjacent genes. ${ }^{C} A T$-skew $=(A-T) /(A+T), G C$-skew $=$ $(G-C) /(G+C) .{ }^{d}$ genes and pseudogenes located in the different strand from that of nad3 are underlined.

Additional file 9: Alignments of putative the pseudogene Pcox1-2 and putative functional gene cox 1 of Liposcelis entomophila.

Consensus sequences are shown in the green background.

\section{Abbreviations}

PCGs: Protein-coding genes; atp6 and atp8: Genes for the ATPase subunits 6 and 8; $\operatorname{cox} 1$-cox3: Genes for cytochrome C oxidase subunits I-III; cob: A gene for apocytochrome b; nad1-nad6 and nad4L: Genes for NADH dehydrogenase subunits 1-6 and 4 L; rrnL: Large (16S) rRNA subunit (gene); rrnS: Small (12S) rRNA subunit (gene); $\operatorname{trn} X$ (where $X$ is replaced by one letter amino acid code of the corresponding amino acid): transfer RNA.

\section{Competing interests}

The authors declare that they have no competing interests.

\section{Authors' contributions}

SCC, DDW and JJW conceived and designed the experiments. SCC, DDW, JXS and WD performed the experiments. SCC analyzed the data. JJW also contributed reagents/materials/analysis tools. SCC, DDW, RS and JJW wrote the paper. All authors read and approved the final manuscript.

\section{Acknowledgments}

This work was supported by the National Natural Sciences Foundation (31301667), the Specialized Research Fund for the Doctoral Program of Higher Education (20100182120022), and the Fundamental Research Funds for the Central Universities (XDJK2013C051, XDJK2013A005) to DDW, WD, and JJW. The Australian Research Council (DP120100240) and Australia-China Science \& Research Fund (ACSRF00980) to RS.

\section{Author details}

${ }^{1}$ Key Laboratory of Entomology and Pest Control Engineering, College of Plant Protection, Southwest University, Chongqing, P. R. China. ${ }^{2}$ Gene Cology Research Centre, Faculty of Science, Education and Engineering, University of the Sunshine Coast, Maroochydore, Queensland, Australia.

Received: 12 June 2014 Accepted: 29 September 2014 Published: 5 October 2014

\section{References}

1. Simon $\mathrm{S}, \mathrm{Hadrys} \mathrm{H}$ : A comparative analysis of complete mitochondrial genomes among Hexapoda. Mol Phylogenet Evol 2013, 69(2):393-403.

2. Bernt M, Braband A, Schierwater B, Stadler PF: Genetic aspects of mitochondrial genome evolution. Mol Phylogenet Evol 2013, 69(2):328-338.

3. Burger G, Gray MW, Lang BF: Mitochondrial genomes: anything goes. Trends Genet 2003, 19(12):709-716.

4. Boore JL: Animal mitochondrial genomes. Nucleic Acids Res 1999 , 27(8):1767-1780

5. Wolstenholme DR: Animal mitochondrial DNA: structure and evolution. Int Rev Cytol 1992, 141:173-216.

6. Wang JP, Cao TW, Xuan SB, Wang H, Zhang M, Ma EB: The complete mitochondrial genome of Sasakia funebris (Leech) (Lepidoptera: Nymphalidae) and comparison with other Apaturinae insects. Gene 2013, 526(2):277-283.

7. Liu QN, Zhu BJ, Dai LS, Liu CL: The complete mitogenome of Bombyx mori strain Dazao (Lepidoptera: Bombycidae) and comparison with other lepidopteran insects. Genomics 2013, 101(1):64-73.

8. Xiao B, Chen AH, Zhang YY, Jiang GF, Hu CC, Zhu CD: Complete mitochondrial genomes of two cockroaches, Blattella germanica and Periplaneta americana, and the phylogenetic position of termites. Curr Genet 2012, 58(2):65-77.

9. Cameron SL: Insect mitochondrial genomics: implications for evolution and phylogeny. Annu Rev Entomol 2014, 59:95-117.

10. Pascual-Villalobos MJ, Baz A, Del Estal P: Occurrence of psocids and natura predators on organic rice in Calasparra (Murcia, Spain). J Stored Prod Res 2005, 41(2):231-235.

11. Roesler R: Die Gattungen der Copeognathen. Stettiner Entomologische Zeitung 1944, 105:117-166.

12. Li H, Shao RF, Song F, Zhou XG, Yang QQ, Li ZH, Cai WZ: Mitochondrial genomes of two barklice, Psococerastis albimaculata and Longivalvus hyalospilus (Psocoptera: Psocomorpha): contrasting rates in mitochondrial gene rearrangement between major Lineages of Psocodea. PLOS ONE 2013, 8(4):e61685.

13. Wei DD, Shao R, Yuan ML, Dou W, Barker SC, Wang JJ: The multipartite mitochondrial genome of Liposcelis bostrychophila: insights into the evolution of mitochondrial genomes in bilateral animals. PLOS ONE 2012, 7(3):e33973.

14. Shao RF, Dowton M, Murrell A, Barker SC: Rates of gene rearrangement and nucleotide substitution are correlated in the mitochondrial genomes of insects. Mol Biol Evol 2003, 20(10):1612-1619.

15. Chen SC, Wei DD, Shao R, Dou W, Wang JJ: The complete mitochondrial genome of the booklouse, Liposcelis decolor: insights into gene arrangement and genome organization within the genus Liposcelis. PLOS ONE 2014, 9(3):e91902.

16. Lienhard C: Nomenclatural amendments concerning Chinese Psocoptera (Insecta), with remarks on species richness. Rev Suisse Zool 2003, 110(4):695-721.

17. Li FS: Psocoptera of China. Beijing: Science Press; 2002:77-79.

18. Lienhard C: Revision of the western palaearctic species of Liposcelis Motschulsky (Psocoptera: Liposcelididae). Zoologische Jahrbücher, Abteilung für Systematik, Ökologie und Geographie der Tiere 1990, 117(2):117-174.

19. Wang ZY, Wang JJ, Lienhard C: Two new species of Liposcelis (Psocoptera, Liposcelididae). Acta Zootaxon Sin 2006, 31(3):564-568. 
20. Nayak MK, Collins PJ, Throne JE, Wang JJ: Biology and management of psocids infesting stored products. Annu Rev Entomol 2014, 59:279-297.

21. Wei DD, Yuan ML, Wang ZY, Wang D, Wang BJ, Dou W, Wang JJ: Sequence analysis of the ribosomal internal transcribed spacers region in psocids (Psocoptera: Liposcelididae) for phylogenetic inference and species discrimination. J Econ Entomol 2011, 104(5):1720-1729.

22. Cheng WX, Dou W, Chai YX, Wang JJ: Comparison of biochemical and toxicological characterizations of glutathione S-transferases and superoxide dismutase between Liposcelis bostrychophila Badonnel and L. entomophila (Enderlein) (Psocoptera: Liposcelididae). Pestic Biochem Phys 2007, 89(2):151-157.

23. Lyal CHC: Phylogeny and classification of the Psocodea, with particular reference to the lice (Psocodea: Phthiraptera). Syst Entomol 1985, 10(2):145-165

24. Yang QQ, Zhao S, Kucerova Z, Stejskal V, Opit G, Qin M, Cao Y, Li FJ, Li ZH: Validation of the $16 \mathrm{~S}$ rDNA and COI DNA barcoding technique for rapid molecular identification of stored product psocids (Insecta: Psocodea: Liposcelididae). J Econ Entomol 2013, 106(1):419-425.

25. Simon C, Frati F, Beckenbach A, Crespi B, Liu H, Flook P: Evolution, weighting, and phylogenetic utility of mitochondrial gene-sequences and a compilation of conserved polymerase chain-reaction primers. Ann Entomol Soc Am 1994, 87(6):651-701.

26. Shao R, Zhu XQ, Barker SC, Herd K: Evolution of extensively fragmented mitochondrial genomes in the lice of humans. Genome Biol Evol 2012, 4(11):1088-1101.

27. Shao RF, Kirkness EF, Barker SC: The single mitochondrial chromosome typical of animals has evolved into 18 minichromosomes in the human body louse, Pediculus humanus. Genome Res 2009, 19(5):904-912.

28. Laslett D, Canback B: ARWEN: a program to detect tRNA genes in metazoan mitochondrial nucleotide sequences. Bioinformatics 2008, 24(2):172-175

29. Lowe TM, Eddy SR: tRNAscan-SE: a program for improved detection of transfer RNA genes in genomic sequence. Nucleic Acids Res 1997, 25(5):955-964.

30. Zuker M: Mfold web server for nucleic acid folding and hybridization prediction. Nucleic Acids Res 2003, 31(13):3406-3415.

31. D'Antonio M, Griggio F, Lupi R, Borsani M, Pavesi G, Castrignano T, Pesole G, Gissi C: MitoZoa 2.0: a database resource and search tools for comparative and evolutionary analyses of mitochondrial genomes in Metazoa. Nucleic Acids Res 2012, 40(Database issue):D1168-D1172.

32. Tamura K, Peterson D, Peterson N, Stecher G, Nei M, Kumar S: MEGA5: molecular evolutionary genetics analysis using maximum likelihood, evolutionary distance, and maximum parsimony methods. Mol Biol Evol 2011, 28(10):2731-2739.

33. Castresana J: Selection of conserved blocks from multiple alignments for their use in phylogenetic analysis. Mol Biol Evol 2000, 17(4):540-552.

34. Xia X, Lemey P: Assessing Substitution Saturation with DAMBE, Phylogenetic Handbook: A Practical Approach to Phylogenetic Analysis and Hypothesis Testing. 2nd edition; 2009:615-630.

35. Posada D: jModelTest: phylogenetic model averaging. Mol Biol Evol 2008 25(7):1253-1256

36. Darriba D, Taboada GL, Doallo R, Posada D: jModelTest 2: more models, new heuristics and parallel computing. Nat Methods 2012, 9(8):772.

37. Darriba D, Taboada GL, Doallo R, Posada D: ProtTest 3: fast selection of best-fit models of protein evolution. Bioinformatics 2011, 27(8):1164-1165.

38. Guindon S, Gascuel O: A simple, fast, and accurate algorithm to estimate large phylogenies by maximum likelihood. Syst Biol 2003, 52(5):696-704

39. Song DS, Barker SC, Shao R: Variation in mitochondrial minichromosome composition between blood-sucking lice of the genus Haematopinus that infest horses and pigs. Parasit Vector 2014, 7(1):144.

40. Dong WG, Song SM, Jin DC, Guo XG, Shao RF: Fragmented mitochondrial genomes of the rat lice, Polyplax asiatica and Polyplax spinulosa: intra-genus variation in fragmentation pattern and a possible link between the extent of fragmentation and the length of life cycle. BMC Genomics 2014, 15:44.

41. Jiang $H$, Barker SC, Shao R: Substantial variation in the extent of mitochondrial genome fragmentation among blood-sucking lice of mammals. Genome Biol Evol 2013, 5(7):1298-1308.
42. Hwang DS, Suga K, Sakakura Y, Park HG, Hagiwara A, Rhee JS, Lee JS: Complete mitochondrial genome of the monogonont rotifer, Brachionus koreanus (Rotifera, Brachionidae). Mitochondr DNA 2014, 25(1):29-30.

43. Suga K, Welch DBM, Tanaka Y, Sakakura Y, Hagiwarak A: Two circular chromosomes of unequal copy number make up the mitochondrial genome of the rotifer Brachionus plicatilis. Mol Biol Evol 2008, 25(6):1129-1137.

44. Gissi C, lannelli F, Pesole G: Complete mtDNA of Ciona intestinalis reveals extensive gene rearrangement and the presence of an atp8 and an extra trnM gene in ascidians. J Mol Evol 2004, 58(4):376-389.

45. Iannelli F, Griggio F, Pesole G, Gissi C: The mitochondrial genome of Phallusia mammillata and Phallusia fumigata (Tunicata, Ascidiacea) high genome plasticity at intra-genus level. BMC Evol Biol 2007, 7:155.

46. Uda K, Komeda Y, Fujita T, Iwasaki N, Bavestrello G, Giovine M, Cattaneo-Vietti R, Suzuki T: Complete mitochondrial genomes of the Japanese pink coral (Corallium elatius) and the Mediterranean red coral (Corallium rubrum): a reevaluation of the phylogeny of the family Coralliidae based on molecular data. Comp Biochem Physiol Part D Genomics Proteomics 2013, 8(3):209-219.

47. Littlewood DT, Lockyer AE, Webster BL, Johnston DA, Le TH: The complete mitochondrial genomes of Schistosoma haematobium and Schistosoma spindale and the evolutionary history of mitochondrial genome changes among parasitic flatworms. Mol Phylogenet Evol 2006, 39(2):452-467.

48. Shao RF, Barker SC, Mitani H, Takahashi M, Fukunaga M: Molecular mechanisms for the variation of mitochondrial gene content and gene arrangement among chigger mites of the genus Leptotrombidium (Acari: Acariformes). J Mol Evol 2006, 63(2):251-261.

49. Shao R, Mitani H, Barker SC, Takahashi M, Fukunaga M: Novel mitochondrial gene content and gene arrangement indicate illegitimate inter-mtDNA recombination in the chigger mite, Leptotrombidium pallidum. J Mol Evol 2005, 60(6):764-773.

50. Klimov PB, Oconnor BM: Improved tRNA prediction in the American house dust mite reveals widespread occurrence of extremely short minimal tRNAs in acariform mites. BMC Genomics 2009, 10:598.

51. Kakehashi R, Kurabayashi A, Oumi S, Katsuren S, Hoso M, Sumida M: Mitochondrial genomes of Japanese Babina frogs (Ranidae, Anura): unique gene arrangements and the phylogenetic position of genus Babina. Genes Genet Syst 2013, 88(1):59-67.

52. Hyman BC, Lewis SC, Tang S, Wu Z: Rampant gene rearrangement and haplotype hypervariation among nematode mitochondrial genomes. Genetica 2011, 139(5):611-615.

53. Mueller RL, Boore JL: Molecular mechanisms of extensive mitochondrial gene rearrangement in plethodontid salamanders. Mol Biol Evol 2005, 22(10):2104-2112.

54. Macey JR, Schulte JA, Larson A, Papenfuss TJ: Tandem duplication via light-strand synthesis may provide a precursor for mitochondrial genomic rearrangement. Mol Biol Evol 1998, 15(1):71-75.

55. Cameron SL, Johnson KP, Whiting MF: The mitochondrial genome of the screamer louse Bothriometopus (Phthiraptera: Ischnocera): effects of extensive gene rearrangements on the evolution of the genome. $J \mathrm{Mol}$ Evol 2007, 65(5):589-604.

56. Mabuchi K, Miya M, Satoh TP, Westneat MW, Nishida M: Gene rearrangements and evolution of tRNA pseudogenes in the mitochondrial genome of the parrotfish (Teleostei: Perciformes: Scaridae). J Mol Evol 2004, 59(3):287-297

57. Raboin MJ, Timko AF, Howe DK, Felix MA, Denver DR: Evolution of Caenorhabditis mitochondrial genome pseudogenes and Caenorhabditis briggsae natural isolates. Mol Biol Evol 2010, 27(5):1087-1096.

58. Howe DK, Denver DR: Muller's Ratchet and compensatory mutation in Caenorhabditis briggsae mitochondrial genome evolution. BMC Evol Biol 2008, 8:62.

59. Gibson T, Blok VC, Phillips MS, Hong G, Kumarasinghe D, Riley IT, Dowton M: The mitochondrial subgenomes of the nematode Globodera pallida are mosaics: evidence of recombination in an animal mitochondrial genome. J Mol Evol 2007, 64(4):463-471.

60. Gibson T, Blok VC, Dowton M: Sequence and characterization of six mitochondrial subgenomes from Globodera rostochiensis: multipartite structure is conserved among close nematode relatives. J Mol Evol 2007, 65(3):308-315 
61. San Mauro D, Gower DJ, Zardoya R, Wilkinson M: A hotspot of gene order rearrangement by tandem duplication and random loss in the vertebrate mitochondrial genome. Mol Biol Evol 2006, 23(1):227-234.

62. Boore $\mathrm{JL}$ : The duplication/random loss model for gene rearrangement exemplified by mitochondrial genomes of deuterostome animals. In Comparative Genomics. Edited by Sankoff D, Nadeau J. Netherlands: Kluwer Academic Publishers, Springer; 2000:133-147.

63. Shao RF, Barker SC: Chimeric mitochondrial minichromosomes of the human body louse, Pediculus humanus: evidence for homologous and non-homologous recombination. Gene 2011, 473(1):36-43.

doi:10.1186/1471-2164-15-861

Cite this article as: Chen et al:: Evolution of multipartite mitochondrial genomes in the booklice of the genus Liposcelis (Psocoptera). BMC Genomics 2014 15:861.

\section{Submit your next manuscript to BioMed Central and take full advantage of:}

- Convenient online submission

- Thorough peer review

- No space constraints or color figure charges

- Immediate publication on acceptance

- Inclusion in PubMed, CAS, Scopus and Google Scholar

- Research which is freely available for redistribution 